\title{
Correction to: DNA barcoding and NMR spectroscopy-based assessment of species adulteration in the raw herbal trade of Saraca asoca (Roxb.) Willd, an important medicinal plant
}

\author{
Santhosh Kumar Jayanthinagar Urumarudappa ${ }^{1,2,3}$ - Navdeep Gogna ${ }^{4} \cdot$ Steven G. Newmaster ${ }^{5}$. \\ Krishna Venkatarangaiah ${ }^{3}$. Ragupathy Subramanyam ${ }^{5}$. Seethapathy Gopalakrishnan Saroja ${ }^{6}$. \\ Ravikanth Gudasalamani ${ }^{6} \cdot$ Kavita Dorai $^{4} \cdot$ Uma Shaanker Ramanan ${ }^{1,2,6}$
}

Published online: 9 August 2021

(c) Springer-Verlag GmbH Germany, part of Springer Nature 2021

Correction to: International Journal of Legal Medicine (2016) 130:1457-1470

https://doi.org/10.1007/s00414-016-1436-y

After publication of this article the authors realised that the Conflict of Interest statement was incomplete. The Conflict of Interest statement should read as follows: "Steven Newmaster was the Co-Founder and Chief Scientific Officer of TRU-ID, a voluntary certification program to ensure botanical ingredients are authentic, which was established by the University of Guelph in 2013 and in which all profits went to support research on authentication of botanicals. TRU-ID closed down in 2020". The authors apologise for this omission.

Additionally, in this article the affiliation details for Author Steven G. Newmaster were incorrectly given as

The original article can be found online at https://doi.org/10.1007/ s00414-016-1436-y

Uma Shaanker Ramanan

umashaanker@gmail.com

1 School of Ecology and Conservation, University of Agricultural Sciences, GKVK, Bangalore 560065, India

2 Department of Crop Physiology, University of Agricultural Sciences, GKVK, Bangalore 560065, India

3 Department of Post Graduate Studies and Research in Biotechnology, Jnanasahyadri, Kuvempu University, Shankaraghatta, Shimoga 577451, India

4 Indian Institute of Science Education and Research (IISER) Mohali, Knowledge City Sector 81, PO Manauli, Mohali, Punjab 140306, India

5 College of Biological Sciences, Department of Integrative Biology, University of Guelph, Toronto N1G 2W1, Canada

6 Ashoka Trust for Research in Ecology and the Environment, Royal Enclave, Srirampura, Jakkur Post, Bangalore 560064, India
'Centre for Biodiversity Genomics (CBG), College of Biological Sciences, Department of Integrative Biology, University of Guelph, Toronto N1G 2W1, Canada' but should have been 'College of Biological Sciences, Department of Integrative Biology, University of Guelph, Toronto N1G 2W1, Canada'.

Publisher's note Springer Nature remains neutral with regard to jurisdictional claims in published maps and institutional affiliations. 